Regular Article

\title{
What to do? Does science have a role?
}

\author{
K. Hasselmann \\ Max-Planck-Institute for Meteorology, Hamburg, Germany, and European Climate Forum
}

\begin{abstract}
A new generation of integrated assessment models of climate change policies is needed to capture the basic dynamical processes that govern the required transformation of the present fossil-based global economic system to a sustainable decarbonized system. After an overview of the abatement technologies and policy instruments that are already available and able today to achieve the transformation, three examples are presented of typical actor-based, systemdynamical models that are able to simulate some of the key dynamics of the transition processes. In addition to developing a new hierarchy of integrated assessment models, scientists need also to better educate the public and policy makers on the wide-reaching implications of the inherent inertia of the climate system.
\end{abstract}

\section{Introduction: The role of science}

The reality of human induced climate change is no longer seriously disputed. With the presentation of the latest (Fourth) Assessment Report of the UN Intergovernmental Panel on Climate Change (IPCC) [15], highlighted by the joint award of the Nobel Peace Prize to IPCC and to $\mathrm{Al}$ Gore for his widely acclaimed climate documentary film "An incovenient truth", and with the publication in the same year of the forceful Review on the Economics of Climate Change by Sir Nicholas Stern [24], the former chief economist of the World Bank, the need to jointly address the challenge of climate change has become a high priority issue for all nations.

Science has played a crucial role in bringing the problem of climate change to the attention of the media, the public and policy makers. Scientists have been warning of the dangers of global warming caused by continually rising emissions of greenhouse gases, predominantly $\mathrm{CO}_{2}$, since the early 1970's. However, it was only with the creation of an official UN Panel, the IPCC, that the voice of science was widely listened to. The first IPCC report in 1990 already had a strong impact on the first Earth Summit in Rio de Janeiro in 1992 (the UN Conference on the Environment and Development, UNCED), and the subsequent IPCC reports have continually increased the public awareness of climate change.

The scientific basis of climate change has been disseminated to the wider public and policy makers primarily through the reports of IPCC Working Group 1 ("The science of Climate Change"). In contrast, the reports of the remaining two IPCC Working Groups (WG 2, "Impacts and Adaptation", and WG 3, "Climate Change Mitigation") have had little influence, both on the public and, more importantly, on climate policies. In part, this is due to the long, typically six-year intervals between successive IPCC reports, which are not in tune with the shorter time scales of policy makers actively engaged in climate negotiations. But, on a more fundamental level, the weak impact must also be attributed to basic shortcomings of the so called integrated assessment models that have been used to analyse climate policies. These have been largely based on general equilibrium models of the economy, or close derivatives thereof. The concept of general equilibrium, although useful in many other areas of economics, fails to capture the dynamical processes that govern the transformation from a fossil-based to a decarbonized economic system $[3,11]$.

In this paper, an overview is given of a proposed new generation of integrated assessment models designed to overcome these shortcomings. The paper is structured as follows. 
As background, an overview is given in Section 2 of the available energy technologies and climate policy instruments that can be applied already today to prevent dangerous global warming, normally defined as a temperature increase of no more than $2^{\circ} \mathrm{C}$ above the pre-industrial level. Section 3 then addresses the question of why traditional integrated assessment models have failed to capture the basic dynamics of the decarbonization transformation. It is argued that economic thinking in general has been undergoing a paradigm shift from models rooted in formal mathematical analysis, including, in particular the general equilibrium concept, to dynamical simulation models that represent the economy as an evolving system governed by the behaviour of individual economic actors pursuing different economic goals. The paradigm shift has influenced many areas of economics, but is only just beginning to penetrate the integrated assessment modeling of climate change.

Examples of some simple dynamical multi-actor models are presented in the subsequent sections 4-6. In view of the great complexity of the coupled climate-socio-economic system, a single model will never be able to address all issues faced by policy makers. The modeling challenge is rather to create a hierarchy of transparent, mutually supporting models that can be readily understood by policy makers. The models presented span both the long term economic evolution characterizing the transition to a decarbonized economy and shorter term instabilities, such as business cycles, financial crises and recessions, that policy makers strive to control at the same time as avoiding dangerous climate change. The model examples are intended as initial contributions to a planned more complete model hierarchy. Some general conclusions are summarized in Section 7.

\section{Abatement technologies and climate policy instruments}

There exists general agreement that the technologies needed to decarbonize the global economy exist already today. At present, most of these are still more expensive than fossil fuels, but the cost relations are inverted if the damage costs of future climate change are properly internalized. Moreover, the present costs of renewable energy are expected to fall through the economies of scale and learning-by-doing once the technologies are implemented on the necessary global scale.

Most estimates of the direct costs of decarbonization lie in the range from $-1 \%$ to $4 \%$ of world GDP, with a mean value of about 1\% [24]. Although this appears large when expressed in dollars or Euros, when viewed over a period of many decades to centuries relevant for climate change, and against the background of a global economy that can be expected to grow at a rate of at least 1-2\% per annum, it translates into a delay in economic growth over this period of only a few months to a year $[2,10]$. This is clearly an acceptable price for avoiding the major risks of dangerous long-term climate change.

The central issue is therefore not whether climate change mitigation is feasible or affordable, but how can it best be implemented: which decarbonization technologies are most promising, in which time frame, and which policy instruments should be applied? The follow-up question (pursued in the next sections) is then: how can science assist policy makers in this decision process?

Figure 1 shows a plausible sequence of decarbonization technologies that could close the wedge between the $\mathrm{CO}_{2}$ emission curve for a typical Business as Usual (BAU) reference scenario and the sustainable-emissions curve required to avoid dangerous climate change [15]. ${ }^{1}$

Many investigations have shown that the most economical method for reducing greenhouse gas emissions is to increase energy efficiency. This can be achieved at near zero or even negative cost, and is therefore assumed to be implemented first. However, since energy use and the associated $\mathrm{CO}_{2}$ emissions can not be avoided entirely, but can only be reduced by a finite factor, in the long term enhanced energy efficiency is unable to counteract the continual growth of emissions, which is driven mainly by the legitimate welfare aspirations of the developing countries.

\footnotetext{
${ }^{1}$ For simplicity, the discussion is limited to the greenhouse gas $\mathrm{CO}_{2}$, which accounts for about $60 \%$ of present greenhouse gas emissions, and is projected to contribute a still larger fraction in the future.
} 


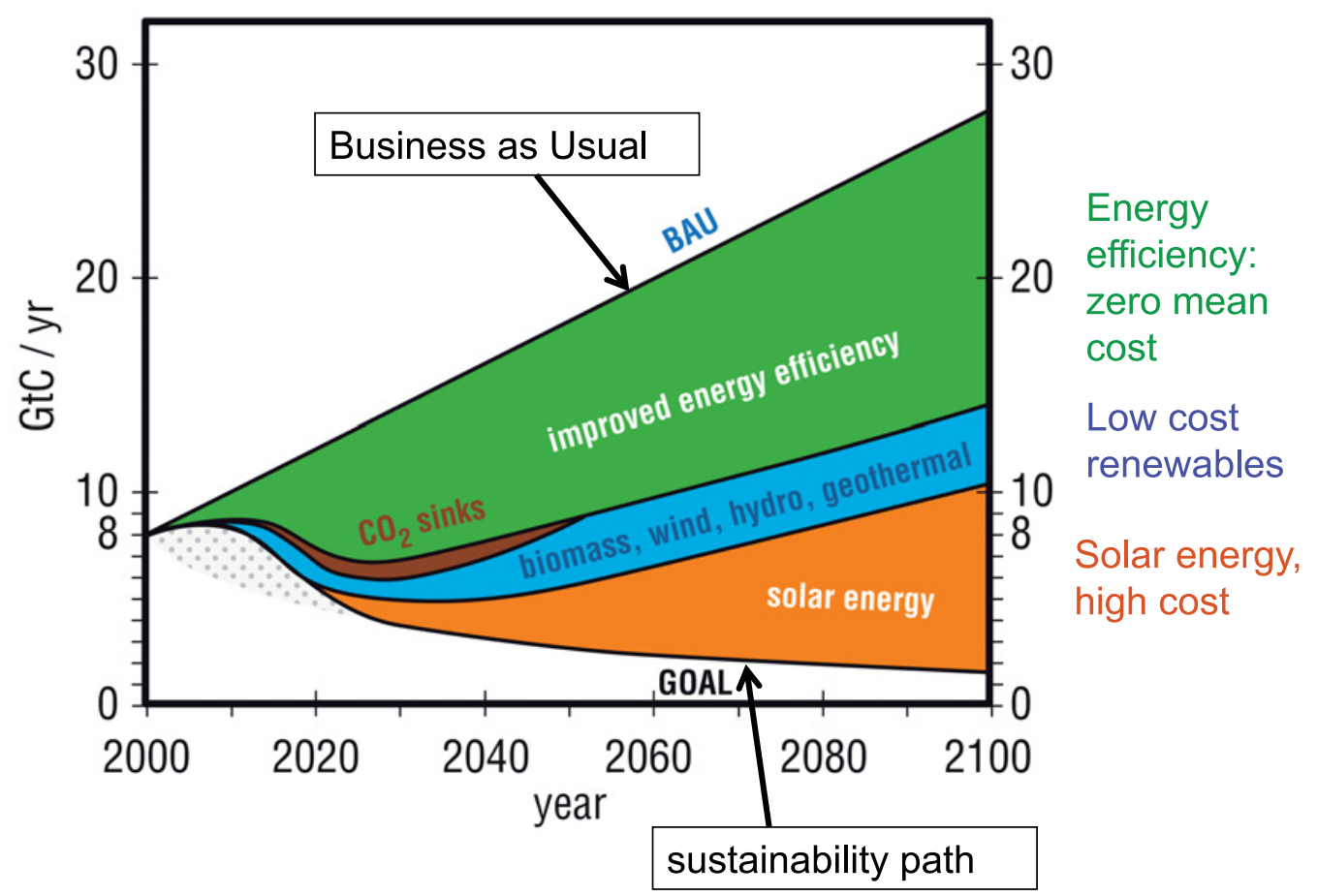

Fig. 1. Closing the wedge between Business as Usual (BAU) emissions and the corresponding curve for sustainable low-carbon emissions. Shown is a plausible scenario for the successive introduction of technologically feasible abatement technologies (enhanced energy efficiency, $\mathrm{CO}_{2}$ sinks through reforestation, biomass-, wind-, hydro-, geothermal and solar energy) dependent on abatement capacities and estimated short and long term costs.

In parallel, but with some delay, the lower-cost renewable energy technologies are then assumed to penetrate the market. However, these technologies $-\mathrm{CO}_{2}$ sinks through reforestation, ${ }^{2}$ biomass, wind energy, geothermal and hydro-power - also have only finite abatement capacities and are therefore similarly unable to satisfy the growing long-term energy needs of the world's population. In the long-term, these can be satisfied only by exploiting solar energy, a virtually unlimited energy source. ${ }^{3}$ An area of about $200 \mathrm{~km} \times 200 \mathrm{~km}$ in the world's deserts could provide sufficient energy to satisfy the world's energy demand in the foreseeable future. However, the present costs for the large-scale introduction of concentrated solar power, including the necessary infra-structure in the form of high-voltage direct-current grids, storage back-up, computerized control of energy use, etc, are higher than the costs of other renewable energy technologies. Thus solar energy will require subsidies to penetrate the market. The central policy problem is then choosing and implementing the proper mix of policy instruments to achieve an optimal balance between shorter-term investments in low-cost renewable technologies and longer-term investments in solar energy.

Governments have available four basic policy instruments to guide investments in the desired direction:

1. Internalization of the future damage costs of climate change through the imposition of a price on $\mathrm{CO}_{2}$ emissions, either directly through a carbon tax or indirectly through an emission-permits trading (cap-and-trade) scheme ("stick" policies).

\footnotetext{
2 Although much discussed, reforestation has only a limited long-term impact, as indicated in Fig. 1, since the net $\mathrm{CO}_{2}$ uptake vanishes once the forests are grown.

3 Other technologies, such as carbon capture and storage, advanced nuclear energy, or fusion, are either unproven, or controversial, and will not be discussed in this brief overview.
} 


\section{fossil energy low-cost renewables high-cost renewables \\ (solar energy)}

\section{1. stick}

(Kyoto, carbon price:

2. carrot

internalize external costs)

(Post-Kyoto: subsidies)

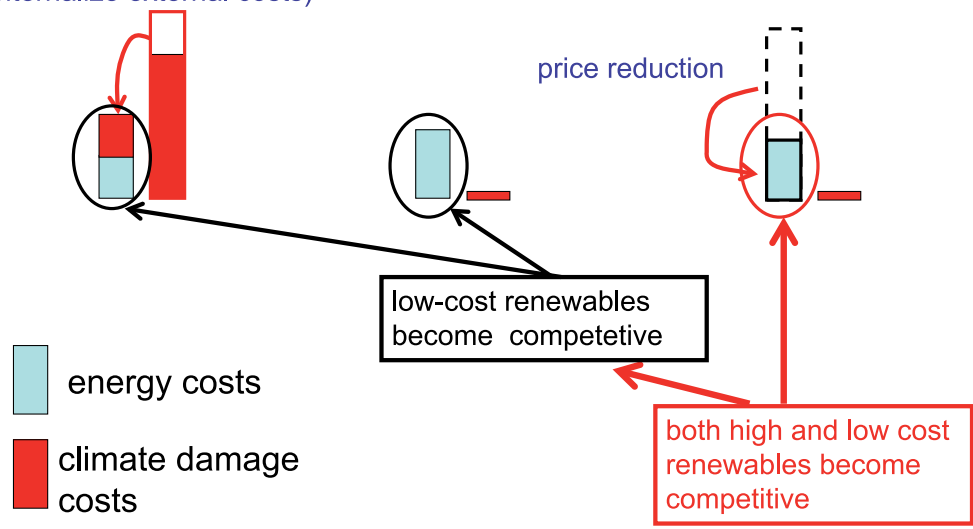

Fig. 2. Replacement of fossil fuels (left) by low and high cost renewables (centre and right, respectively) through application of stick and carrot policies (carbon price and subsidies). Blue columns: basic energy production costs; red columns: future climate damage costs. Low-cost renewables become competitive alone through stick policies (internalization of climate damage costs) while high-cost renewables require in addition carrot policies (subsidies) to penetrate the market and exploit cost reductions through economies of scale and learning-by-doing.

2. Subsidies for technologies (such as concentrated solar power) that are not yet competitive in the market place, even with the introduction of a moderate carbon price, but are nevertheless needed in the longer term ("carrot policies").

3. Emission regulations for sectors that are not exposed to or are not sufficiently responsive to market forces (e.g. automobile emissions, building insulation, lighting, household appliances, ..)

4. Financial and technological transfers from developed countries with high per capita emissions to emerging and developing countries with low per capita emissions, for example, through the allocation of equal per capita emission rights to all countries in a global capand-trade scheme (thereby generating income for countries with low per-capita emissions through the sale of initially surplus emission rights to countries with higher per-capita emissions).

Figure 2 illustrates the impact of a combination of the first two policy instruments, carbon prices and subsidies. A carbon price "stick", as implemented in the Kyoto cap-and-trade scheme, ${ }^{4}$ internalizes the external climate damage costs of fossil fuels. This shifts part of the future costs of climate change to the present costs of fossil fuels (red arrow in Fig. 2), enabling lower-cost renewable energy technologies to become competitive. However, higher-cost energy technologies, such as solar energy, remain uncompetitive unless supported additionally by subsidies ("carrot" policies, indicated by the second red arrow in Fig. 2). Although occasionally (inappropriately) criticized as distorting the market, subsidies are essential societal investments that are justified economically by the longer-term time horizons of public investments (low discount factors) as opposed to the shorter-term horizons of private investments (high discount factors).

Unfortunately, not all sectors of the economy are sufficiently exposed to market forces to respond to market instruments. For example, affluent automobile owners may be unwilling to switch to low-fuel vehicles to avoid the higher fuel costs imposed by a carbon tax. Similarly, limited economic incentives or information barriers hinder the wide-spread voluntary introduction of efficient household appliances, low-energy light bulbs, building insulation, etc. In these

\footnotetext{
4 Unfortunately, the Kyoto emission trading scheme was largely ineffective, as too many permits were allocated, and these were furthermore distributed free of charge instead of auctioned.
} 


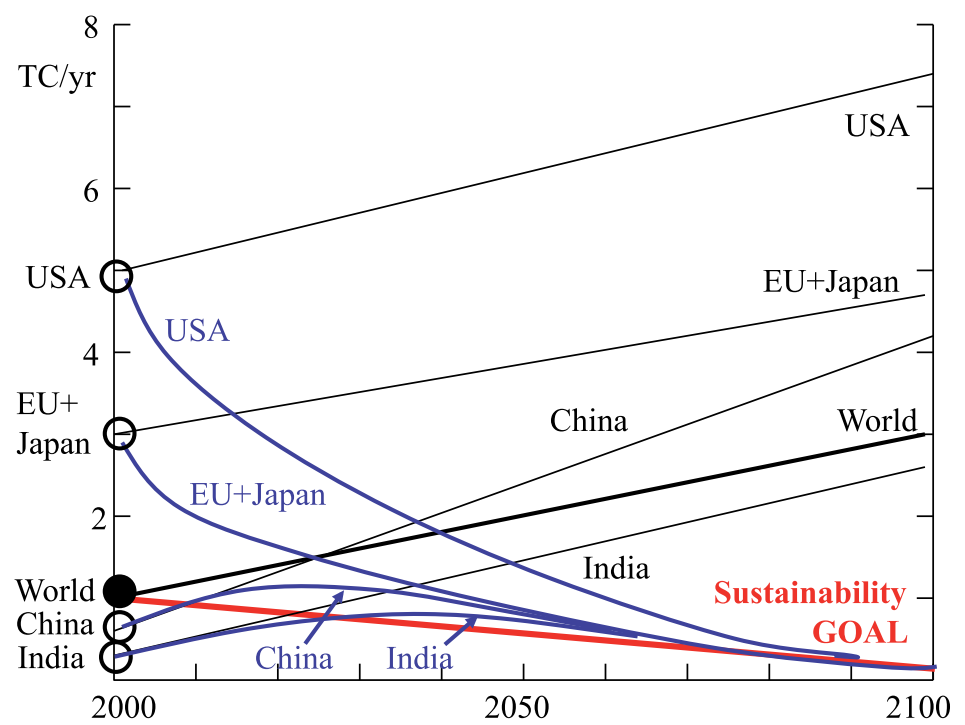

Fig. 3. Estimated linearly extrapolated $\mathrm{BAU}$ per capita $\mathrm{CO}_{2}$ emissions, in tonnes carbon per year (TC/yr), for industrialized and emerging countries, together with the convergence-and-contraction emission curves required to achieve a sustainable long-term low-carbon economy.

cases, appropriate regulations are needed, and have proven to be effective without imposing significant hardships.

Figure 3, finally, illustrates the need to augment national abatement policies with international agreements on financial and technological transfers from high to low per-capita emission countries. Shown as examples are per-capita $\mathrm{CO}_{2}$ emission curves for the industrial countries USA and EU+Japan and the emerging economies China and India. The linearly growing emission curves correspond to plausible BAU scenarios, while the downwards turning curves represent the emissions needed to arrive at a low-carbon global economy. The curves clearly demonstrate that to reduce global emissions to levels consistent with the global sustainability trajectory of Fig. 1, the industrial countries will need to reduce emissions much more strongly than the emerging - or still more so, the developing - countries. Moreover, the curves indicate that the emerging and developing countries will need to reduce emissions significantly even before the per capita emissions of all countries have significantly converged. This will presumably be acceptable to countries whose per-capita emissions are still significantly lower than those of the industrialized countries only if the latter are willing to support the abatement efforts of the emerging and developing countries with major transfers of capital and technology.

\section{The paradigm shift in economic theory}

As already mentioned, the focus on computable general equilibrium (CGE) models in most integrated assessments of climate policies fails to address many of the major concerns of policy makers. While important aspects such as trade and price formation are well represented by CGE models, other important issues are not. In particular, the impact of climate policies on the many dynamical adjustment processes accompanying globalization cannot be captured from an equilibrium perspective. For example, the immigration pressures and conflict potentials arising from increasing rich-poor inequalities between developed und developing countries are a major problem already today, and are expected to be further exacerbated by climate change. Also excluded in CGE models, but central for policy makers, is the inter-relation between longterm climate policies and short-term monetary and fiscal policies designed to stabilize financial markets and economic growth - as highlighted by the major global financial crisis and recession of 2008 . 
The origin of this disconnect must be sought in the history of macroeconomics. Traditional macroeconomics has been built on two basic pillars: the mental models of classical economists, and formal mathematical analysis. Our present understanding of how the economy works is still strongly anchored in the mental models developed by a formidable succession of economic thinkers, beginning with Francois Quesnay and Adam Smith in the 18th century, and continuing with David Ricardo, Karl Marx, John Maynard Keynes, Joseph Schumpeter and Milton Friedman into the late twentieth century, to name but a few. Attempts to underlay or extend these concepts, beyond explanatory graphs, with rigorous mathematical analysis, beginning in the late 19th century, led then to an equally impressive series of theoretical constructs, from general economic equilibrium theory - the centrepiece of mathematical macroeconomics created by Walras (1874) [26] - to econometrics and statistical inference, the theory of economic growth, and game theory.

However, it has always been recognized that the enormously complex macroeconomic system, governed by the multiple interactions of innumerable, notoriously unpredictable human agents, can be made amenable to formal mathematical analysis only by introducing highly restrictive simplifications. These have often been motivated more by the desire to arrive at analytically manageable (preferably conceptually elegant) mathematical structures, rather than the wish to accurately translate the mental models of the classical economists into mathematical formalisms. Thus the relation between the mental models of the classical economists and formal mathematical analysis has always been rather tenuous and controversial.

This is particularly pronounced for the general theory of economic equilibrium. Whereas general equilibrium theory postulates a balance between supply and demand, yielding an economic growth path corresponding to an optimal allocation of resources, with full employment, near-zero profits and optimal investments in capital, the mental models of most classical economists have been concerned with deviations from this ideal state, focussing on the different roles and conflicting economic goals of different actors, the causes of unemployment, distributional inequalities with associated potential for social strife, and instabilities such as business cycles, recessions, financial crises, etc.

The different viewpoints correspond to the different roles played by the economic actors in the two classes of model. In general equilibrium theory, all economic actors are assumed to have perfect knowledge and foresight, thereby behaving as universally predictable system components. Thus the theory is in effect actor independent. In contrast, classical mental models are strongly anchored in human behaviour, different models being distinguished by the different behavioral patterns assumed for different economic actors. ${ }^{5}$

With the advent of increasingly powerful computers, however, many of the technical difficulties hindering the translation of classical mental models into mathematics amenable to formal analysis could be simply side-stepped by direct computer simulation. This has motivated a plethora of new approaches, beginning with the world model developed in the ground breaking simulations of the Club of Rome [18]. Many of the later models fall within the general class of multi-agent simulations, referred to variously as agent-based computational economics [25], multi-agent systems $[1,8]$, or, in a more general context, evolutionary economics [19], complexity economics [4], post-Walrasian economics [5] or simply system dynamics [22].

The common goal of most of these multi-agent approaches is to derive the characteristic features of macroeconomic systems as "emergent properties" of microeconomic systems governed by the interactions between (typically a large number of) individual agents. The simulations have been successful in explaining many of the interesting and often puzzling features of macroeconomic systems, such as the large volatilities, non-Gaussian fluctuation statistics, unanticipated major instabilities, or the emergence of complex networks of interacting agents. However, apart from a few exceptions (e.g. $[6,20]$ ), the bottom-up approach has not yet yielded macroeconomic models that can be usefully applied for policy advice, particularly with respect

\footnotetext{
5 Even Adam Smith [21], whose famous "invisible hand" is widely invoked as justification for the general equilibrium concept, argued that economic growth is driven by the technological innovative efforts of individual entrepreneurs striving to escape the erosion of profits by competitors, rather than the savings of consumers made available for business investments, as assumed in most general equilibrium models.
} 
to climate change. For lack of an alternative, most integrated assessments of climate change have accordingly been carried out using available general equilibrium models, although the limitations of these models are now well known (cf. $[3,7])$.

We argue that the route to agent-based macroeconomic models need not necessarily follow the rather tedious path from high to low resolution. System reduction is routinely achieved in physics and other fields by introducing heuristic assumptions, which can then be tested against data and, if feasible, a few selected high resolution simulations. In fact, most mental models of the classical economists use a heuristic approach. In accordance with this view, we present in the following sections three simple examples of agent-based models defined from the start as top-down models. The dynamics of these models are governed by the actions of a small number of representative economic actors. The approach leads to transparent models that can readily communicated to policy makers and stakeholders. We prefer to use the term actor rather than agent, as in contrast to the frequent use of the term agent as an arbitrary entity in a model that can interact with other entities, as in an object-oriented program (cf. [25]), our agents refer to real people pursuing individual economic goals.

Our modeling approach is hierarchial. The global climate-socioeconomic system in its entirety is clearly far too complex to be described adequately by a single model. Our strategy is accordingly to decompose the complete system into a set of sub-systems that highlight particular aspects of the complete system. The sub-system models are designed such that several simple models can be combined into a more complex integrated model, or, alternatively, simple models can be upgraded into more complex models by including further processes. In either approach, the complexity of the resultant model is limited ultimately by the availability of data to test the model. By adopting a hierarchial strategy, one can check at each model level whether the model still lies within the testability limits.

Our model examples represent components of a more complete model hierarchy MADIAMS (Multi-Actor Dynamic Integrated Assessment Model System) currently in development. The first model corresponds to the original coupled climate-socioeconomic model MADIAM of Weber et al. [27]. MADIAM consists of a representative-actor macroeconomic model coupled to a nonlinear impulse response sub-system model of the climate-carbon-cycle system [13]. Our second model extends MADIAM by including shorter-term actor behaviour that can lead to instabilities, such as business cycles or assett-market bubbles. This is important for the assessment of climate policies applied to a global economic system that has a demonstrated susceptibility to major instabilities and breakdowns. The third model, finally, generalizes both models through the introduction of further actors engaged in the long chain of processes extending from the initial generation and transmission of scientific information on climate change through IPCC to the final impact of the implemented policies on climate change. An effective scientific assessment of mitigation policies needs to be based on an adequate understanding of the many delays and hindrances encountered in this complete end-to-end process chain.

\section{The MADIAM model}

MADIAM combines a traditional macroeconomic model representation in terms of a standard state vector $\mathbf{x}=\left(x_{1}, x_{2}, \ldots\right)=\left(x_{j}\right)$ of aggregated economic variables with a dynamical representation of the evolution of the system that depends on the actions of a small number of representative agents, characterized by a set of actor control variables $\mathbf{z}=\left(z_{1}, z_{2}, \ldots\right)=\left(z_{j}\right)$. The evolution of the system is accordingly described by a set of coupled differential equations

$$
\frac{d \mathbf{x}}{d t}=\mathbf{F}(\mathbf{x}, \mathbf{z})
$$

in which the individual control variables $z_{j}(t)$ at time $t$ are functions of the present and past values of the state vector and can also depend (in the case of more sophisticated inter-actor strategies) on past values of the control variables. The control variables represent parameters in a set of control algorithms describing either the strategies of individual actors (for example, with 
respect to the investment decisions of firms) or the outcome of negotiations between different actors (for example, in the determination of wage levels).

The actors correspond to the representative actors of standard economics, namely: firms, which decide on investments and (in cooperation with workers) on wage levels; households, which decide on consumption, savings and (in their role as workers) on wage levels; governments, which decide on the level and recycling of carbon taxes; and banks, which control the money supply.

As state variables we choose again the standard variables of economic growth models: physical capital (sub-divided into fossil energy, non-fossil energy, and non-energy related physical capital), human capital (representing the net sum of education, technological know-how, institutions, ..), and consumer goods and services (sub-divided into climate-friendly and non-climatefriendly goods). The production function is similarly represented in the traditional manner as a function of physical capital, human capital, employed labor and available natural resources.

However, in contrast to most growth models, physical capital and labor are not treated as substitutable. Instead, following Leontief [16], it is assumed that the level of technology (human capital) determines the amount of labour that can be economically employed for a given level of capital. This has two important consequences: first, it implies that economic growth is driven by investments in technology (as argued already by Adam Smith); second, if employment and wage levels are high, firms are motivated to invest in human capital rather than physical capital, resulting in higher labor productivity but lower employment levels. Ultimately, a growth path is established in which investments in physical and human capital are balanced at a finite level of structural unemployment, dependent, among other factors, on the outcome of wage negotiations. These are rather common-sense conclusions which cannot be captured and quantified, however, in the traditional actor-independent treatment of economic growth.

We refer to Weber et al. [27] for a more detailed analysis of the impact of various actor strategies on economic growth under different climate policies. Important for the outcome are not only the investment decisions of firms, but also consumer preferences for climate-friendly goods over non-climate-friendly goods, and the fraction of carbon taxes recycled into subsidies for renewable energy technologies. Figure 4 shows as example the impact on climate-related variables and various economic parameters of a carbon tax with and without recycling into subsidies for renewable energies. The principal results are summarized in Fig. 5, which underlines the comment made earlier that dangerous change can be avoided through appropriate climate polices (in this case a recycled carbon tax) at an acceptable price of only a minor delay in long-term economic growth.

MADIAM has a number of limitations. In particular, it is restricted to a single economic region (the world, or a single country), and short-term instabilities have been filtered out. It is planned to overcome both restrictions in higher model levels. In the following section we describe the model modifications needed to simulate instabilities such as business cycles, recessions and financial crises.

\section{Simulation of economic instabilities}

Economic instabilities were filtered out in the basic MADIAM version of Weber et al. [27] through the assumption that the market for consumer goods and services (denoted in the following simply as consumer goods) was cleared: all consumer goods were assumed to be bought and consumed at the same rate as they were produced, so that the stock of consumer goods remained constant (and could be ignored as a variable). The only stock variables in which the rate of production was not balanced by an equally large loss rate were physical capital (in its various forms) and human capital. By dropping this assumption and treating consumer goods also as a stock variable, one obtains a model that can develop various forms of actor-dependent instabilities. Although well known and extensively treated in the economic literature, these contradict the classical "invisible hand" hypothesis of economic equilibrium theory, which assumes that any imbalances between supply and demand are automatically counteracted by the response of the economic actors and removed. 

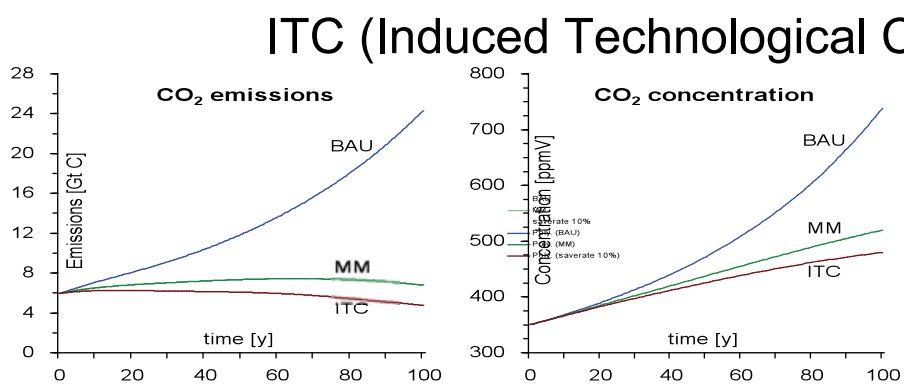

Change)
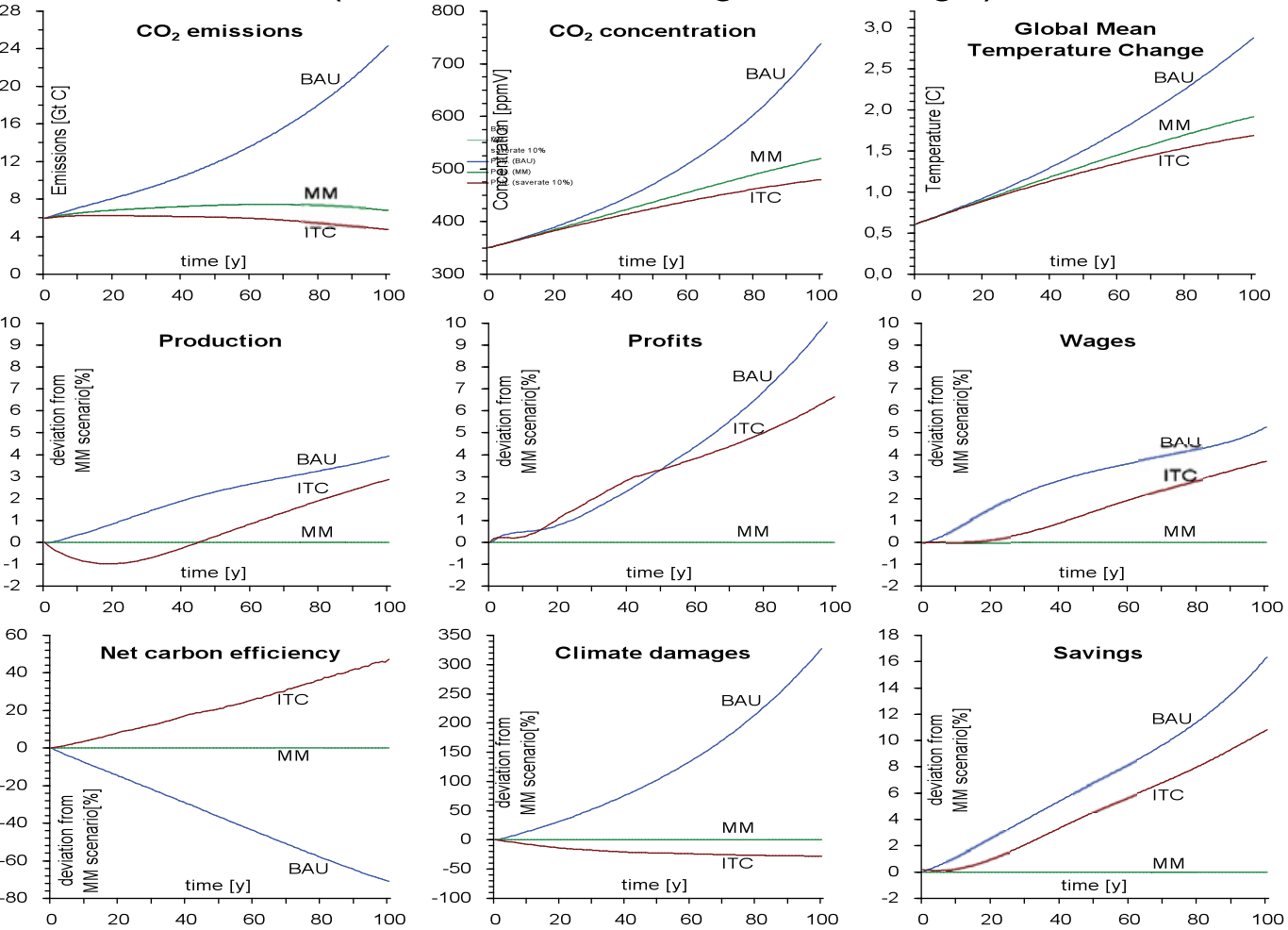

Fig. 4. Impact on climate and economic parameters of a carbon tax (moderate mitigation policy, MM) and a carbon tax recycled into subsidies for renewable energies (induced technological change, ITC). BAU (business as usual) curves are shown for comparison.

\section{mitigation measures: $\quad \mathrm{w}$ : weak, m: moderate, $\mathrm{s}$ : strong}
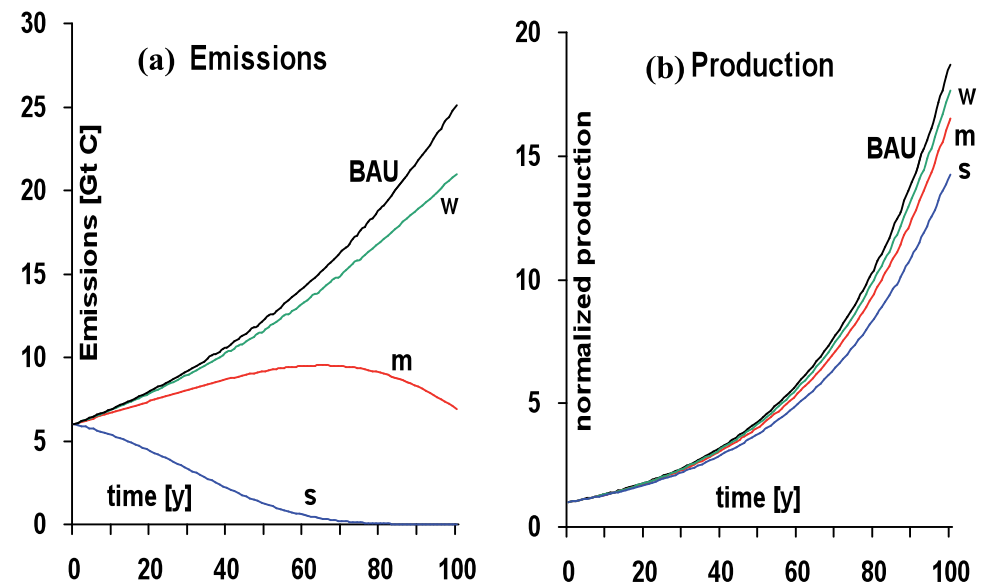

Fig. 5. Impact of weak, moderate and strong mitigation policies on $\mathrm{CO}_{2}$ emissions (left panel) and economic production (right panel), compared against the business-as-usual scenario (BAU). 

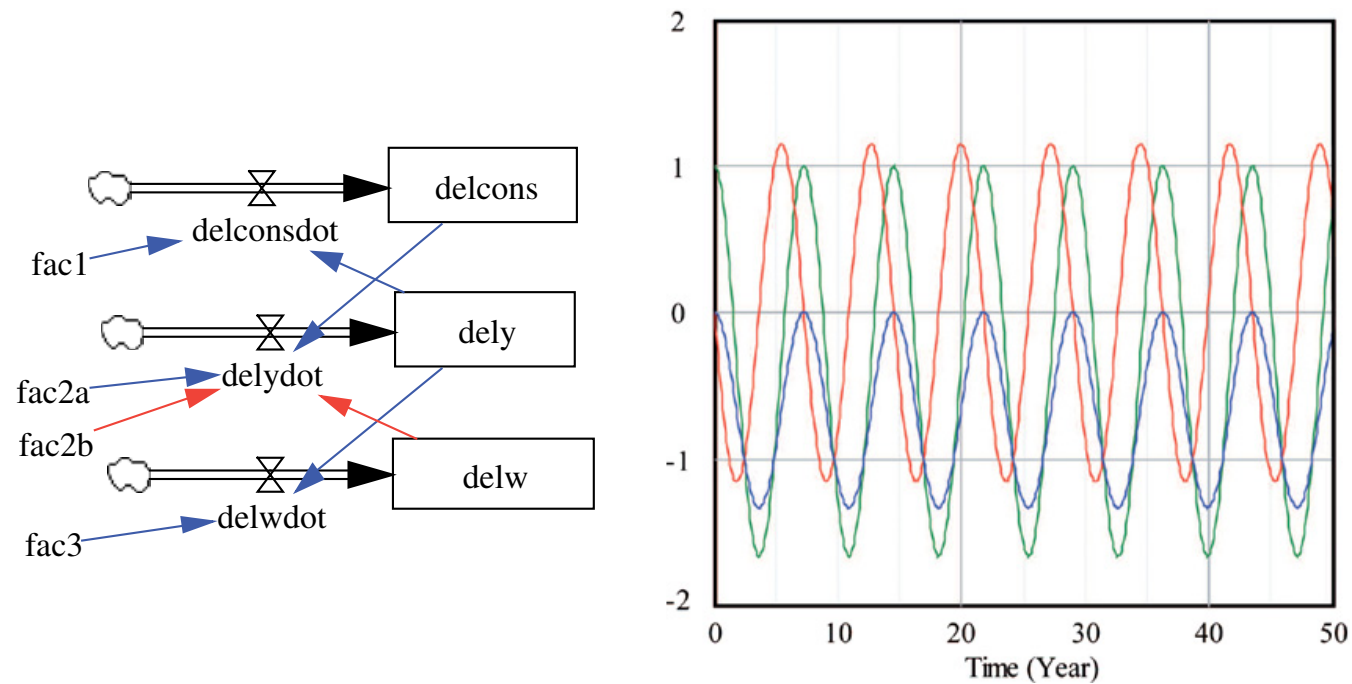

Fig. 6. Left panel: business cycle model of feedbacks between modifications of consumption (delcons), production (dely) and wage levels (delw). Hour glasses denote rates of change (flows), boxes integrated variables (stocks), blue and red lines represent positive and negative feedbacks, respectively. The variables fac1, .., fac3 denote feedback coefficients which control whether the instabilities lead to oscillations or exponential decay or growth. Right panel: a resulting oscillation, in normalized units (delcons: blue; dely: red: delw: green.

Figure 6 shows as example a model of a business cycle resulting from unstable interactions between firms and households. The left panel shows the feedbacks associated with a slow-down in production (dely) by firms responding to a decrease in household consumption (delcons) (triggered, for example, by some random external event). The reduced production, associated with lay-offs, etc, induces a decrease in consumer confidence and thereby a further reduction in consumption. This positive feedback loop in itself (top two boxes) would produce an unstable exponential collapse of production and consumption: a recession (or, alternatively, a boom, depending on the initial conditions). However, for a suitable choice of feedback factors, the instability is converted into a periodic cycle through a stabilizing negative feedback loop (bottom two boxes), representing in this case the willingness of firms to employ more labor once wages have been sufficiently depressed by the reduced employment level.

There exist, of course, many alternative models of business cycles and recessions (e.g. [14,17]; however, common to most models is the positive feedback loop of the top two boxes of Fig. 6). It is important to include these various hypotheses of actor behaviour explicitly in the model in order to study their impact on other model properties, in particular, on the effectiveness of longer-term climate mitigation policies. In the present case, for example, the representation of consumer goods as a stock variable not only enabled the generation of business cycles and other short-term instabilities (see next example), but also modified the long-term economic growth paths. These were found to depend now on the longer-term supply-response strategies of firms to longer-term changes in the demand for consumer goods - a degree of freedom which was surpressed in the previous market-clearing treatment of consumer goods $[9,12]$.

Common to most forms of instabilities are self-fulfilling actor prophesies of future price evolution. Classical example are bubbles and busts in assett and housing markets, which triggered the 2008 global financial crisis. This is in conflict with standard economic theory, which states that supply and demand of a given good always stabilize through market feedbacks to an equilibrium price. If the price is inceased, demand decreases, and vice versa, while supply adjusts to both demand and price, increasing, for example, with demand only if the price is higher than the equilibrium price. Figure 7 shows as example four relaxation trajectories for a simple model realization of this concept.

In contrast, in assett or housing markets, increasing prices can lead to increasing rather than decreasing demand, since buyers speculate that the value of the assett or house will increase 

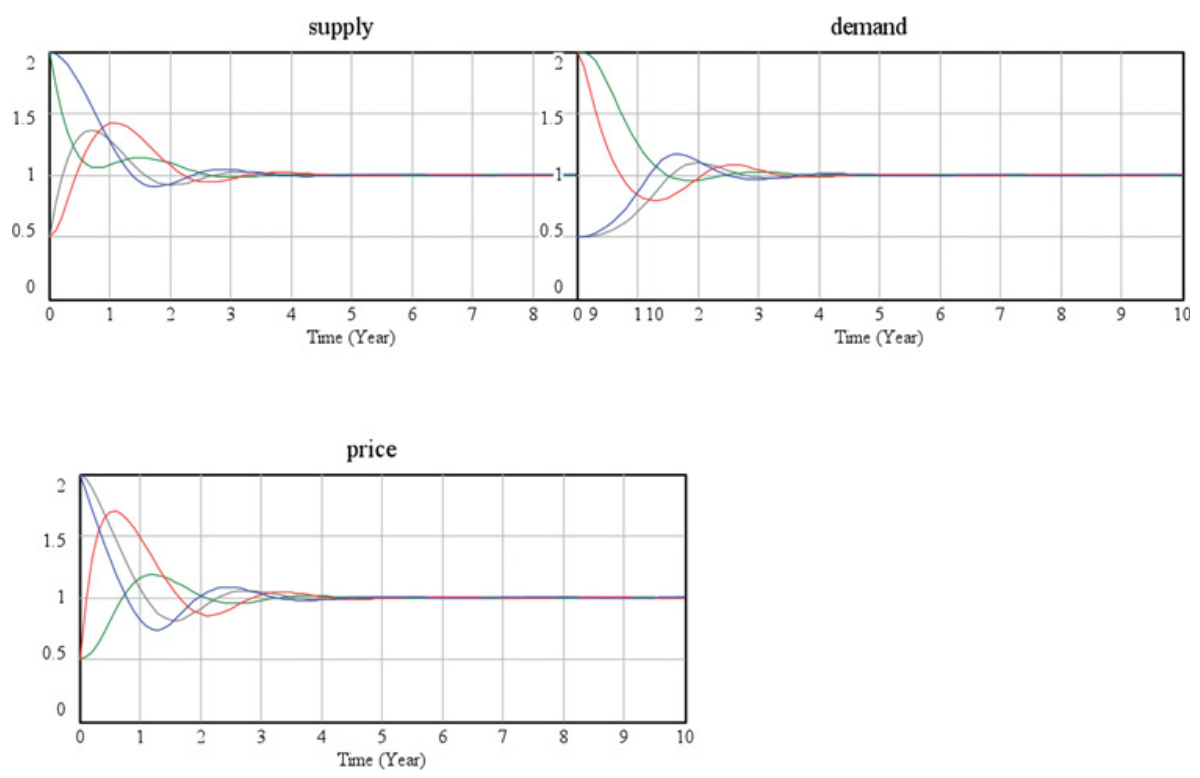

Fig. 7. Adjustment of supply, demand and price to their equilibrium values according to standard economic theory for four different non-equlibrium initial values.
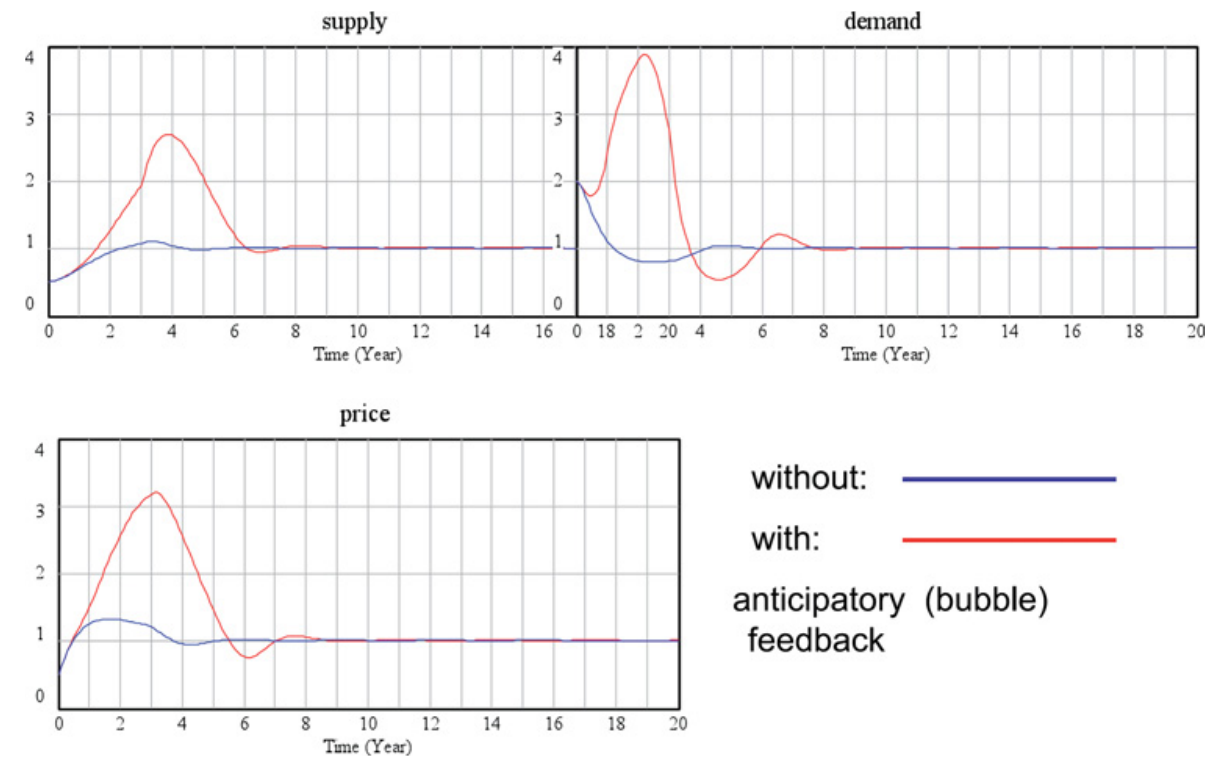

Fig. 8. Bubble and bust sequence produced by speculative anticipation of price developments.

still further in the future. The demand begins to flatten out only when the price of the assett or house has reached a very high level above its true value. At the point where the demand and consequently the price begins to flatten, the anticipation of future decreases in price transforms the boom very rapidly into a bust. Figure 8 shows a simple model realization of the boom and bust concept, simulated by an appropriate modification of the feedbacks of Fig. 7 .

The decarbonization of the present fossil-based global economic system will require major redirections of global investment streams into renewable energy technologies. Many of these investments will necessarily be associated with considerable risk, since the optimal future mix of renewable energy technologies cannot be reliably predicted. It is therefore esential that realistic models of the financial system are included in coupled climate-socio-economic models used for the assessment of climate policies, and that the inherent instabilities of the financial system 


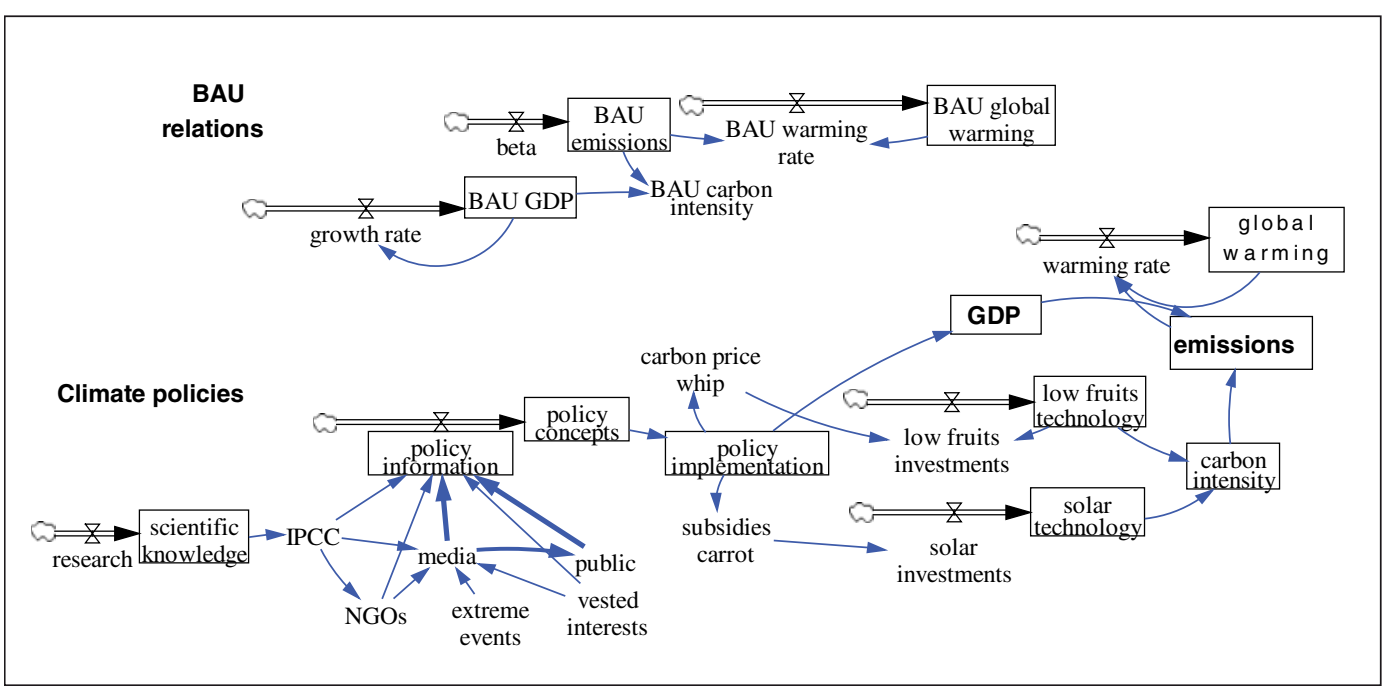

Fig. 9. Information flow rates and political and technological responses (represented by integrating box variables) that characterize the delay chain from the creation of scientific knowledge to the final reduction of global warming. Top sketch: without climate policy (business as usual, BAU); bottom sketch: with climate policy.

are appropriately represented. This will require, of course, a more detailed analysis, including government policies, than can be indicated in this brief overview.

\section{From scientific analysis to mitigation of climate change}

For a more complete understanding of the role of science in the assessment of climate policies, we need to consider not only the many open questions regarding the impact of climate policies, as discussed briefly above, but also the many hindrances and delays encountered in the complete chain of processes leading from the initial creation and dissemination of scientific knowledge on the physics of the climate system to the final outcome of mitigation policies. In addition to the principal economic actors, this requires consideration of further actors involved in the processes of communication of information and policy creation. Figure 9 represents an attempt to capture these processes in a rudimentary manner using a strongly reduced but appropriately augmented version of MADIAM.

The model consists of a complex delay chain, beginning with the first comprehensive presentation of climate-science knowledge through the creation of IPCC in 1990, followed immediately by a contamination of this information by special interest groups opposed to climate change policies, and disseminated (after the addition of further noise through the amplification of pseudo-scientific debates) by the media. These signals, despite the super-imposed noise, nevertheless stimulate first climate policy concepts, which are then elaborated and implemented after further delays, resulting finally in appropriate technological investments (Fig. 10a) to reduce greenhouse gas emissions (Fig. 10b).

A distinction is made in Fig. 10a between investments in low-fruits renewable technologies (wind and hydro power, biofuels,...) that can become competitive already through a carbon tax or a cap-and-trade system ("stick" policies) and high-fruits technologies (e.g. concentrated solar power) that require additional subsidies ("carrot" policies) to penetrate the market. The final global warming and associated economic growth paths for one particular (optimistic) scenario are shown in Figs. 10d, 10c, together with the corresponding curves for the IPCC Business as Usual (BAU) scenario.

The simulations highlight the delays incurred in the cascade from information transfer to policy implementation, while confirming the previous results of Weber et al. [27] and the Stern report [24] that dangerous climate change can be avoided at only minor long-term cost. 


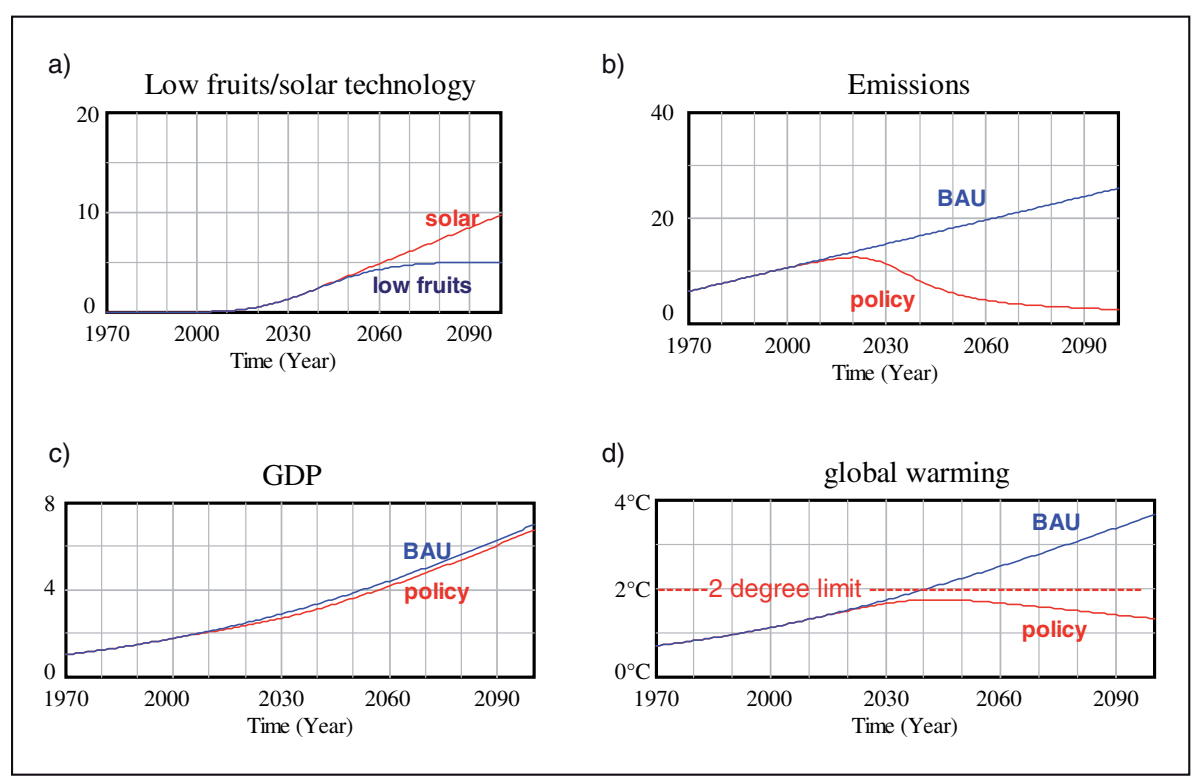

Fig. 10. Resultant evolution of low-fruits and high-fruits (solar) technologies (panel a), $\mathrm{CO}_{2}$ emissions (panel b), global warming (panel d) and GDP (panel c) for the information-to-policy-implementation delay chain of Fig. 9. Also shown in panels b, $\mathrm{c}$ and $\mathrm{d}$ are the corresponding curves for the reference "Business as Usual" (BAU) scenario.

Inspection of the critical bottle-necks of Fig. 9 underline that science has an important role to play, not only in generating an improved understanding of the inter-relation between climate change and climate policy, but also in educating the public and policy makers on the inherent delays built into the climate system. This mandates early action to prevent dangerous long-term climate change - an imperative of climate policy that is not yet widely appreciated (cf. [22]).

\section{Conclusions}

In this necessarily brief overview of the role of science in relation to climate policies, the focus has been on mitigation rather than adaptation. This is motivated in part by the consensus that climate change mitigation is far less costly than adapting to unmitigated climate change. However, some level of anthropogenic climate change (discernibly with us already today) is unavoidable, so that adaptation measures are undoubtedly necessary. The main reason that this issue was not addressed is that adaptation policies are necessarily reactive, rather than proactive. They thereby lack the critical time delay aspects, emphasized in the previous section, which call for a stronger involvement of scientific analysis in climate policy assessments.

The IPCC has played a crucial role in bringing the problem of climate change to the attention of the general public and policy makers. However, IPCC Working Group 3, concerned with mitigation, has been far less influential than Working Group 1 on the science of climate change. We attribute this to the traditional emphasis in macroeconomic modeling on general equilibrium theory. Computable General Equilibrium (CGE) models fail to capture the essential dynamical processes, with their inherent time delays and potential instabilities, that govern the transformation from a fossil-based to a decarbonized global socio-economic system. Needed are simpler simulation models that focus on the key actor-dependent dynamics of the transition process.

Economic theory in general is experiencing a paradigm shift from formal mathematical analysis, in which general equilibrium concepts have played a central role, towards computerbased simulation models that can more easily capture the many fruitful concepts developed in the dynamical, actor-based mental models of classical economists. The paradigm shift is only just beginning to penetrate the field of integrated assessment of climate change, but can be expected to have strong influence in the future also in this area. 
In view of the great complexity of the coupled global climate-socio-economic system, a single model will never be able to simulate all aspects of the system dynamics. Needed is a hierarchy of interrelated models that focus on different, complementary properties of the complete system. It is hoped that the overview given here of some possible components of such a model hierarchy will stimulate similar efforts by scientists contemplating on "What to do".

This work has profited considerably from many stimulating discussions with colleagues from the European Climate Forum, whose contributions are gratefully acknowledged. The work has been partially supported through the networking project "Global Systems Dynamics and Policies" within the Future and Emerging Technologies (FET) programme of the Seventh Framework Programme for Research of the European Commission, under the FET-Open grant agreement GSD, number 221955.

\section{References}

1. R.L. Axtell, in Multi-agent Systems Macro: A Prospectus, in Post Walrasian macroeconomics, edited by D. Colander, 203-220 (Cambridge University Press, 2006), p. 416

2. C. Azar, S.H. Schneider, Are the economic costs of stabilizing the climate prohibitive?, Ecol. Econ. 42, 73-80 (2002)

3. T. Barker, The Economics of Avoiding Dangerous Climate Change, an editorial essay, Climatic Change 89, 173-194 (2008)

4. E. Beinhocker, The Origin of Wealth (Harvard Business School Press, 2006), p. 527

5. D. Colander, Post Walrasian Macroeconomics (Cambridge University Press, 2006), p. 416

6. B. de Vries, SUSCLIME: a simulation/game on population and development in a climateconstrained world, Simul. Develop. 29, 216-237 (1998)

7. O. Edenhofer, K. Lessmann, C. Kemfert, M. Grubb, J. Köhler, Induced Technological Change: Exploring its Implications for the Economics of Atmospheric Stabilization: Synthesis Report from the Innovative Modeling Comparison Project, The Energy J. Spec. Iss. 57-107 (2006)

8. J.M. Epstein, R. Axtell, Growing Artificial Societies, Washington, D.C. (Brookings Institution Press, Cambridge, MA: MIT Press, 1996), p. 208

9. K. Hasselmann, Simulating human behavior in macroeconomic models applied to climate change, Dahlem Conference "Is there a mathematics of social entities", Berlin, 14-20 Dec. (2008) (to be published)

10. K. Hasselmann, M. Latif, G. Hooss, C. Azar, O. Edenhofer, C.C. Jaeger, O.M. Johannessen, C. Kemfert, M. Welp, A. Wokaun, The Challenge of Long-Term Climate Change, Science 302, 1923-1925 (2003)

11. K. Hasselmann, T. Barker, The Stern Review and the IPCC fourth assessment report: implications for the interaction between policymakers and climate experts. An editorial essay, Clim. Change 89, 219-229 (2008)

12. K. Hasselmann, D. Kovalevsky, C. Jaeger, A system dynamics approach to the integrated assessment of climate change (2009) (in preparation)

13. G. Hooss R. Voss, K. Hasselmann, E. Maier-Reimer, F. Joos, A nonlinear impulse response model of the coupled carbon cycle-climate system (NICCS), Clim. Dyn. 18, 189-202 (2001)

14. P. Howitt, in Monetary Policy and the Limits of Economic Knowledge, in Post Walrasian macroeconomics, edited by D. Colander (Cambridge University Press, 2006), p. 416

15. IPCC, Intergovernmental Panel on Climate Change, Fourth Assessment Report, Working Groups 1, 2 and 3 (three volumes), (Cambridge University Press, 2007) (online: http://www.ipcc.ch/ipccreports/ar4-wg1,-wg2,-wg3.htm)

16. W. Leontief, The Structure of the American Economy: 1919-1929 (Harvard University Press, Cambridge, MA, 1951) 2nd enlarged ed., p. 264

17. R.E. Jr. Lucas, Models of Business Cycles, (Oxford, Blackwell, 1987), p. 115

18. D.H. Meadows, D.L. Meadows, J. Randers, W.W. Behrens III, Limits to Growth, Potomac Associates (New York, 1972), p. 207

19. R.R. Nelson, S.G. Winter, An Evolutionary Theory of Economic Change (Cambridge, MA, Belknap Press of Harvard University Press, 1982), p. 437

20. C. Roorda, B. de Vries, K. Lindgren, SUSCLIME: Exploring Strategies for Resource Depletion and Climate Change, draft document, 2008 
21. A. Smith, An Inquiry into the Nature and Causes of the Wealth of Nations, 1776, Reprint edition, New York (Modern Library, 1994), p. 1131

22. J.D. Sterman, Business Dynamics (New York, McGraw-Hill, 2000), p. 982

23. J.D. Sterman, Risk communication on climate: mental models and mass balance, Science $\mathbf{3 2 2}$, $532-533(2008)$

24. N. Stern, The economics of climate change. The Stern Review (Cambridge Univ. Press, 2007), p. 692 (HM Treasury, online: http://www.hm-treasury.gov.uk/stern_review_report.htm)

25. L. Tesfatsion, in Computational modeling and macroeconomics, in Post Walrasian macroeconomics, edited by D. Colander, 175-202 (Cambridge University Press, 2006), p. 416

26. L. Walras, Elements of Pure Economics, 1874, translated by W. Jaffé, George Allen and Unwin (London, 1954), p. 620

27. M. Weber, V. Barth, K. Hasselmann, A Multi-Actor Dynamic Integrated Assesment Model (MADIAM) of Induced Technological Change and Sustainable Economic Growth, Ecol. Econom. 54, 306-327 (2005) 